\title{
MONTANI, Rodrigo. El mundo de las cosas entre los wichis del Gran Chaco: un estudio etnolinguiístico. Cochabamba: ILAMIS: Itinerarios, 2017.607 p.
}

María Agustina Morando*

*Consejo Nacional de Investigaciones Científicas y Técnicas / Universidad de Buenos Aires - Buenos Aires, Argentina agusmoar@gmail.com 
El estudio etnográfico de lo material es una de las tantas formas de intentar comprender el estudio de la realidad indígena. Desde mediados del siglo XIX en adelante, la etnografía sudamericana comienza a rescatar el estudio de la cultura material indígena y es extensa la lista de trabajos que, a partir de esa época, han comenzado a registrar los artefactos utilizados por los indígenas junto a sus nombres, sus usos y los materiales y las técnicas involucrados en su manufactura. Sólo por traer aquí algunos ejemplos, podemos mencionar la propuesta de trabajo de Günter Tessmann (1930) sobre la cultura material de los grupos indígenas del noroeste del Perú, que compara la presencia o ausencia y tipos de distintas categorías de elementos como arcos y flechas, cerbatanas, tambores, adornos, canoas, utensilios domésticos, canoas, vestimenta, cerámica, y tejidos; o también los trabajos de Walter Roth $(1910,1924,1929)$ sobre la manufactura de hilados de algodón y otras fibras, trampas y armas, viviendas, adornos, enseres domésticos, canastos, hamacas entre los indígenas de la Guyana Británica. Para la etnografía del Chaco, engrosan la lista las ricas etnografías de Erland Nordenskiöld (1912), Alfred Métraux $(1942,1948,1996)$ y Max Schmidt (1938) en las cuales, a pesar de la gran variedad de temas, no quedan de lado las extensas descripciones de viviendas, los adornos, los enseres, las armas, la cerámica, los vestidos de los indígenas del Gran Chaco, especialmente para los indígenas chiriguano y chané. También podríamos incluir dentro del repertorio a los estudios de Theodor Koch-Grünberg (1908a, 1908b, 1908c, 1908d) sobre los arcos, flechas, arpones, redes de pesca y armas de caza entre los indígenas del noroeste brasileño, especialmente en la zona comprendida entre los ríos Caiarí y Uaupés.

El mundo de las cosas entre los wichís del Gran Chaco de Rodrigo Montani se integra a este universo de investigaciones que exploran la cultura material indígena sudamericana pero desde un enfoque singular, cuyo fin es adentrarse en el universo material de los wichís poniendo en evidencia los múltiples vínculos que éste mantiene con el conjunto de la vida sociocultural y con la lengua del grupo. Desde un punto de vista más inmediato y pragmático, la obra procura desentrañar el vasto y complejo panorama del mundo de los objetos entre los wichí, lo cual lleva inevitablemente a adentrarse en las formas en las que éstos se posicionan dentro de una red más amplia de prácticas sociales, económicas, políticas, rituales, tecnológicas, etc. consideradas en su contexto particular e histórico. Para ello Montani retiene y problematiza el concepto nativo 
de "cosa" (en wichí "lëkäy") como categoría general que condensa el amplio y heteróclito conjunto de entidades físicas estudiadas en el libro, y que sirve de puntapié inicial para adentrarse en el mundo material.

Así planteada, la descripción del mundo material de los wichí comienza desde lo más amplio y general, especificando y caracterizando los distintos espacios por los que los indígenas transitan cotidianamente al interior de sus comunidades: la vivienda (lëwet), el templo religioso (nohusewet), la escuela (nochujwehnyajwet o eskwela), el puesto sanitario, el centro comunitario (sentlo), el cementerio (lëp’itsehnyëy-wet), la troja (puche o puche-hi), la chacra (lëkäs-wet). Para cada uno de ellos Montani realiza una precisa descripción de los distintos objetos que contienen a su vez. Sólo por citar un ejemplo, al describir el espacio ocupado por el templo evangelista explora asimismo una serie de elementos cotidianos que hacen a la materialidad de este contexto: nolhäk-wet (el "altar" cuya traducción más literal sería la "morada del alimento de alguien”), nonayti (la "pila bautismal" o "recipiente para bañarse de alguien") o nolhämet-wet (el "púlpito" o "morada de la palabra") (p. 165).

Parte de este complejo repertorio del mundo material está conformado por un conjunto de bienes personales que el autor llama "artefactos de la persona" $\mathrm{y}$ que tiene un peso importante a la hora de definir la identidad social del individuo. Dentro de esta categoría caen la vestimenta, los accesorios, las herramientas, las armas y los juguetes tanto de niños y niñas como de adultos.

El universo de los objetos también abarca los instrumentos musicales: las flautas (lëjwol) de hueso o de caña hueca, las arpas de boca (ëjwol o lëkats'unaj), los arcos musicales (lëka yelataj-chäswole), los violines y los tambores (pim-pim, lë[ka]pum o lëkajwitsukw). El repertorio material de lo sonoro también incluye otra serie de elementos adquiridos mediante el contacto con el mundo criollo, algunos nombrados mediante préstamos del castellano y otros con términos wichí. Algunos de estos artefactos son las radios (lëkaitäj) o los grabadores, casetes, celulares y micrófonos, todos referidos con el mismo nombre: lëp’ak-hi.

No quedan de lado en el análisis aquello que el autor denomina "artefactos de figuración", más comúnmente llamados, aunque de forma poco precisa, "artesanías". Dentro de esta categoría caen aquellos objetos que tienen una importante circulación dentro del mercado, como por ejemplo bolsas de chaguar, tallas de madera, mates grabados, figuras de hilo, collares de semillas, canastos, fuentes, cucharas, tenedores, cazuelas y, en menor medida, bateas y morteros. 
Otra arista importante es el análisis de la incorporación a la vida cotidiana de los wichí de nuevos tipos de objetos, muchos de ellos de manufactura industrial, a partir del contacto con el mundo occidental. Algo acerca de lo cual se llama la atención puntualmente es la adaptación de los nombres de estos objetos mediante su incorporación al léxico en tanto préstamos o calcos, o bien mediante la creación de nuevos nombres en wichí. Esto último abre una puerta importante para el estudio de los mecanismos de generación léxica en esta lengua.

Ahora bien, no sólo estos objetos entran dentro del gran conjunto de "lëkäy" sobre el cual versa esta obra. Algunos animales y plantas, por ejemplo, también se incluyen dentro de este continuum de artefactos. En el caso puntual de los animales, por ejemplo, vale la pena llamar la atención sobre el ejemplo del perro: la decisión de incluirlo es que, además de ser una "mascota" o "animal de compañía", es un importante "implemento para la caza" (p. 298). Dentro del conjunto de las plantas llama especialmente la atención la descripción de aquellas que ostentan propiedades mágicas y/o medicinales (es preciso señalar que dentro de la esfera de los elementos medicinales no sólo podemos encontrar plantas sino también plumas, huesos, cenizas, rocas e insectos). Estas plantas son llamadas "samokw" de modo general y dentro de esa categoría podemos mencionar varias especies como "kahumnatsetaj" (planta para enamorar), "otichuhnayajcha" (planta que sirve para superar los desencuentros amorosos), "hataj" (cebil) y "yokwas" (tabaco) (p. 276, 277, 374, 375, 376, 378), etc.

La inclusión de parte de la flora y la fauna dentro del estudio del mundo material wichí lleva también a Rodrigo Montani a plantear el proceso inverso, i.e las propiedades anímicas y vitales que pueden tener ciertos artefactos, fundamentalmente desde un punto de vista cosmológico. Tal es el caso de la historia de "Tío Travieso y las cosas animadas" (p. 62), en la cual se narra cómo el Tío Travieso creó a las víboras a partir de una cuerda, el perro a partir de una figura de barro, los zancudos a partir de granos de arena. De ese modo puede decirse que la cosmología wichí, no sólo revela presuntos aspectos anímicos y vitales de los objetos sino también su origen y las formas en que fueron repartidos en el mundo: así, por ejemplo, en la historia "El reparto de los bienes en el mundo" o "El origen de la desigualdad entre indios y cristianos" (p. 55), se narra la negociación de los bienes materiales del mundo -proceso a través del cual los blancos, en detrimento de los indígenas, han logrado obtener los metales y las armas de fuego. 
Teniendo en cuenta esto, podemos concluir que este trabajo aspira a la construcción de un conocimiento etnográfico totalizador de la cultura wichí tomando como punto de entrada las distintas dimensiones de lo material. El extenso repertorio de cosas que se listan constituye una sólida base para reflexionar acerca de las redes de relaciones que se tejen entre las esferas de lo material, la memoria histórica, la corporalidad, las jerarquías, la organización social, la lengua, la memoria histórica, las relaciones interétnicas, lo estético, la cosmología e incluso la relación que este grupo indígena mantiene con el medioambiente.

Una parte fundamental del estudio es el análisis de los nombres, que en tanto entidades acústico-ideacionales establecen un vínculo con el objeto de referencia que, de alguna forma, también resulta indispensable para reconocerlo y clasificarlo. Tal y como plantea Montani, el estudio morfológico y semántico de las categorías lingüísticas ofrece un punto de partida importante para comprender las relaciones entre las personas y sus cosas. Lejos de ser estático y fijo, el mundo material wichí se mantiene en un estado de constante cambio, lo cual también le ha permitido a Montani trabajar sobre las formas en las que los wichí se posicionan frente a un mundo en el que los artefactos se encuentran cada vez en mayor circulación y de esta forma articulan su modo de vida con la modernidad.

El análisis de todos estos aspectos, en definitiva, permite echar una mirada crítica hacia el interior del mundo material wichí, un mundo hondamente complejo en su estructura interna, haciendo emerger las relaciones que los indígenas mantienen con sus cosas -las cuales se constituyen, en definitiva, como acción social. A través de sus agudas y extensas descripciones que logran transportar la imaginación del lector al Chaco, sin dudas esta obra constituye una fuente rebosante de informaciones misceláneas y completas, imprescindibles para comprender mejor la realidad del pueblo wichí.

\section{Referencias}

KOCH-GRÜNBERG, T. Der Fischfang bei den Indianern Nordwestbrasiliens. Globus, Braunschweig, v. 93, n. 1, p. 1-6, 1908a.

KOCH-GRÜNBERG, T. Der Fischfang bei den Indianern Nordwestbrasiliens (Schluß). Globus, Braunschweig, v. 93, n. 2, p. 21-28, 1908b. 
KOCH-GRÜNBERG, T. Jagd und Waffen bei den Indianern Nordwestbrasiliens. Globus, Braunschweig, v. 93, n. 13, p. 197-203, 1908c.

KOCH-GRÜNBERG, T. Jagd und Waffen bei den Indianern Nordwestbrasiliens (Schluß). Globus, Braunschweig, v. 93, n. 14, p. 215-221, 1908d.

MÉTRAUX, A. The native tribes of Eastern Bolivia and Western Matto Grosso. Washington: United States Government Printing Office, 1942.

MÉTRAUX, A. Tribes of the Eastern Slopes of the Bolivian Andes. Chiriguano and Chané. In: STEWARD, J. H. (Ed.). Handbook of South American Indians: vol. 3 : the tropical forest tribes. Washington: Smithsonian Institution, 1948. p. 465-485.

MÉTRAUX, A. Etnografía del Chaco. Asunción: Editorial El Lector, 1996.

NORDENSKIÖLD, E. Indianerleben: El Gran Chaco (Südamerika). Leipzig: Albert Bonnier, 1912.

ROTH, W. E. Some technological notes from the Pomeroon District, British Guiana. Journal of the Royal Anthropological Institute of Great Britain and Ireland, London, v. 40, p. 72-82, 1910.

ROTH, W. E. An introductory study of the arts, crafts and customs of the Guiana Indians. New York: Johnson Reprint, 1924.

ROTH, W. E. Additional studies of the arts, crafts and customs of the Guiana Indians, with special reference to those of Southern Guiana. Washington: U.S. G.P.O, 1929.

SCHMIDT, M. Los Chiriguanos e Izozós. Revista de la Sociedad Científica del Paraguay, Asunción, v. 4, n. 3, p. 1-115, 1938.

TESSMANN, G. Die Indianer Nordost-Perus: grundlegende Forschungen für eine systematische Kulturkunde. Hamburg: Friederichsen, De Gruyter \& Co., 1930. 